\title{
Carbon C 11 PBR-28
}

National Cancer Institute

\section{Source}

National Cancer Institute. Carbon C 11 PBR-28. NCI Thesaurus. Code C121962.

A radioconjug ate composed of a lig and for the $18 \mathrm{kDa}$ translocator protein (TSPO) conjug ated to the radioisotope carbon C 11, that can be used as a diagnostic imaging agent to detect TSPO-expressing cells using positron emission tomography (PET). Upon administration of carbon C 11 PBR-28, the PBR-28 moiety targets and binds to TSPOexpressing cells. Upon PET, carbon C 11 can be detected and TSPO-expressing cells can be visualized. This can facilitate detection of inflammatory sites and cancer cells. TSPO, also called the peripheral benzodiazepine receptor (PBR), is found on the outer mitochondrial membrane and is overexpressed on a variety of cancer cells and during inflammation. 